\title{
Association between Percentage of Body Fat in Normal Body Mass Index Subjects and Type 2 Diabetes Mellitus in Iraqi Population: Case Control Study
}

\section{Salam Jasim Mohammed ${ }^{*}$}

Family and Community Medicine Department, University of Kufa, Iraq

*Corresponding author: Salam Jasim Mohammed, Family and Community Medicine Department, Faculty of Medicine, University of Kufa, Iraq, Tel: 009647812535432; E-mail: salam.alfatlawi@uokufa.edu.iq

Received date: October 11, 2017; Accepted date: October 27, 2017; Published date: October 30, 2017

Copyright: () 2017 Mohammed SJ. This is an open-access article distributed under the terms of the Creative Commons Attribution License, which permits unrestricted use, distribution, and reproduction in any medium, provided the original author and source are credited.

\begin{abstract}
Obesity is a major risk factor for type 2 diabetes mellitus development. For measurement of obesity, defined as an excess in fat of the body, body mass index (BMI) is usually used, but this measure underestimates obesity prevalence. We performed a case control study including 558 known diabetic subjects who were on oral hypoglycemic drugs and 2175 matched control group. BMI and body fat percent were determined by bioelectrical impedance (In-body 370). Age, Gender and body mass index show no significant difference between the two groups $(p>0.05)$. Odds ratio for development of type 2 diabetes mellitus among high percentage body fat was $2.72(95 \% \mathrm{Cl}$ 2.21-3.35), so we conclude that excess body fat even with normal body mass index had about 2.7 times risk for type 2 diabetes mellitus development.
\end{abstract}

Keywords: Body mass index; Diabetes mellitus type 2; Obesity

\section{Introduction}

The prevalence of obesity is increasing rapidly all over the world [1]. Obesity is defined as accumulation of excess amount of fat in the body and is known to be a risk for many disease states such as dyslipidemia, hypertension, and ischemic heart disease [2]. It has been found that obese persons are at higher risk of type 2 diabetes, liver disease, heart disease, sleep-breathing disorders, and many types of cancers [3].

BMI has been classically used as an approximate measure of adiposity and is commonly used for diagnosis and classification of obesity. However, it is well known that development of glucose intolerance and type 2 diabetes mellitus is strongly influenced by body fat distribution [4], waist-hip ratio or waist circumference is a better predictor of the obesity-associated type 2 diabetes [5]. There are very few studies measuring the metabolic risk factors associated with body fat percentage [BF\%] [6]. BF\% is good indicator of obesity related to morbidity like cardiovascular disease than circumference of the waist [7]. Additionally, $\mathrm{BF} \%$ has been associated with all-cause and cardiovascular mortality $[8,9]$. Mortality is strongly associated with high body fat mass than BMI [10]. Therefore, it is important to study the clinical benefit of measuring $\mathrm{BF} \%$ to estimate the obesityassociated type 2 diabetes risk.

The study aim was to evaluate the impact of body fat percent on the development of type 2 diabetes. Therefore, we conducted a case control study evaluating the association between $\mathrm{BF} \%$ and type 2 diabetes in person with normal BMI.

\section{Patients and Methods}

We conducted a case control study of 2733 subjects (1913 females/820 males), aged 35-60 years including patients visiting the private clinic for nutritional diseases in Al-Najaf city-Iraq. The study was performed to evaluate the relationship between type 2 diabetes and the body fat percent in normal BMI subjects. Patients divided into two groups, group one patients with diabetes and they are on oral hypoglycemic drugs but not insulin and they are matched for age and sex with control group without diabetes by history and by confirmation by investigation (fasting blood sugar). All patients with normal body mass index had been included in the study. The study last for three years (march-2014/march-2017). Informed consent was obtained from all subjects

After taking the required information from subjects by data collection form, In-body 370 had been used to measure body mass index $\left\{\right.$ weight (kilogram)/height $\left(\right.$ meter $\left.\left.^{2}\right)\right\}$ and body fat percentage for all subjects. Body mass index regarded normal when it is between 18.5$25 \mathrm{~kg} / \mathrm{m}^{2}$ as defined by world health organization and percentage of body fat regarded normal if it is between $18-28 \%$ of the body for females and $10-20 \%$ for males as it is measured by In-body 370 machine (Biospace, In-body, korea). Subjects had been sent for laboratory investigation including fasting blood sugar The analysis of plasma glucose was done by an automated analyzer (Roche/Hitachi Modular P800; Basel, Switzerland) [11,12]. The project was approved by the ethical committee of college of medicine; university of Kufa (reference code MECCM-03) Statistical analysis was done by using SPSS (statistical package for social sciences) version 20. We use mean with standard deviation and frequency with percentages as descriptive statistics. Chi square test used for analysis of categorical variables and independent sample t-test used for analysis of continuous variables. To measure the risk we commute odds ratio. $\mathrm{P}$ value $\leq 0.05$ regarded significant.

\section{Results}

A total of 2733 subjects had been included in this study. The diabetics were 558 while the controls were 2175 . The baseline characteristics of the studied subjects had been shown in Table 1 . 


\begin{tabular}{|c|c|c|c|c|}
\hline \multicolumn{2}{|l|}{ Variable } & $\begin{array}{l}\text { Diabetics } \\
(n=558)\end{array}$ & $\begin{array}{l}\text { Control } \\
(n=2175)\end{array}$ & $P$ value \\
\hline \multicolumn{2}{|l|}{ Age/years } & $44.6 \pm 7.91$ & $45.2 \pm 8.82$ & 0.059 \\
\hline \multirow[b]{2}{*}{ Gender } & Male & $166(29.7 \%)$ & $654(30 \%)$ & \multirow[b]{2}{*}{0.883} \\
\hline & Female & $392(70.3 \%)$ & $1521(70 \%)$ & \\
\hline \multirow[b]{2}{*}{ Residence } & Rural & $133(23.8 \%)$ & $451(20.7 \%)$ & \multirow[b]{2}{*}{0.111} \\
\hline & Urban & $425(76.2 \%)$ & $1724(79.3 \%)$ & \\
\hline \multicolumn{2}{|c|}{ Body mass index } & $24.2 \pm 1.5$ & $24.3 \pm 1.4$ & 0.077 \\
\hline \multicolumn{2}{|c|}{ Hypertension } & $178(31.9 \%)$ & $701(32.2 \%)$ & 0.882 \\
\hline \multicolumn{2}{|c|}{ Family history of DM } & $96(17.2 \%)$ & $304(13.9 \%)$ & 0.063 \\
\hline \multirow{2}{*}{$\begin{array}{l}\text { Smoking/ } \\
\text { cigarettes }\end{array}$} & $0-20$ & $211(37.8 \%)$ & $899(41.3 \%)$ & \multirow[b]{2}{*}{0.144} \\
\hline & $>20$ & $347(62.2 \%)$ & $1276(58.7 \%)$ & \\
\hline
\end{tabular}

Table 1: Baseline characteristics of studied subjects.

Table 1 shows no significant difference between diabetics and control group in all baseline characteristics $(p>0.05)$

\begin{tabular}{|c|c|c|c|}
\hline & $\begin{array}{l}\text { Diabetes mellitus } \\
(n=558)\end{array}$ & $\begin{array}{l}\text { Control } \\
(n=2175)\end{array}$ & Odds ratio( $95 \% \mathrm{Cl})$ \\
\hline High BF\% & 211(37.8\%) & $397(18.3 \%)$ & \\
\hline Normal BF\% & $347(62.2 \%)$ & 1778(81.7\%) & $2.72(2.21-3.35)$ \\
\hline
\end{tabular}

Table 2: Association between percentage of body fat and diabetes mellitus.

In Table 2 there is significant association between percentage of body fat and diabetes mellitus type 2 , so those with high body fat percent had 2.7 times risk of developing diabetes mellitus type 2 compared to those with normal body fat percent $(\mathrm{BF} \%)$.

\section{Discussion}

Obesity represents an excess of body fat and it is the major risk factor for type 2 diabetes mellitus development and the development of co morbidity increase with increase amount of this fat [13]. The present study provides evidence that evaluating the risk of type 2 diabetes even in normal BMI subjects should include measurement of $\mathrm{BF} \%$, especially those over the age of 40 in both genders. The epidemiological studies that analyze the association between $\mathrm{BF} \%$ and diabetes mellitus type 2 are scarce despite of the fact that the risk of type 2 diabetes increased when there is excess adiposity. There are few studies that analyze the effect of $\mathrm{BF} \%$ on levels of metabolic risk factor have focused more on the effect of distribution of body fat rather than studying the effect of the increment of adiposity in the body itself [14-16] or have been done only in volunteers with lean range BMIs [16]. Our results show that the actual amount of body fat is also playing a key role in the insulin resistance development as shown in Table 2 where the percentage of type 2 DM higher compared to control group in those with high BF\%. This result has a very important clinical implementation where the American Diabetes Association (ADA) recommends screening for prediabetes each three years for subjects older than 45 years with BMI $\geq 25 \mathrm{~kg} / \mathrm{m}^{2}$ while the screening for those $<45$ years age only if BMI $\geq 25$ and another risk factor present [17].

Really, in daily clinical work this recommendation for screening is infrequent [18]. In our result there is evident effect of increased BF\% on development of type 2 diabetes, So this study give us scientific explanation that the composition of the body may help to understand the metabolic effect of high BF\% in normal BMI subjects [6,19]. Other researchers find that the diabetes type 2 risk can be predicted similarly by abdominal and overall adiposity [20,21]. Biggs et al. [22] recently have shown that central and overall adiposity in addition to weight increment in middle age and over 65 years have association with type 2 diabetes mellitus risk, with this finding even they use body fat mass measured in kilogram for analysis and not BF\%. Our findings show that in individuals with lean-BMI , $\mathrm{BF} \%$ may be more important than BMI. Moreover, adipose tissue from visceral and subcutaneous fat has been associated with inflammation and oxidative stress markers $[23,24]$. BF\% possibly is better predictor for risks associated with obesity than adiposity distribution indicators like circumference of the waist especially in male [25]. Another point that can be concluded from our finding is that there is under diagnosis of obesity in clinical practice due to depending on BMI only and this lead to missed opportunities to manage such conditions. This observation suggests that the BMI limits used for diagnosing obesity may need reevaluation. The present study may have a limitation regarding the validity of inbody 370 in measurement of $\mathrm{BF} \%$. In summary, individuals with normal BMI not mean they haven't adiposity, so BF\% must be measured and it may be more determinant than BMI for type 2 diabetes mellitus development. There is under diagnosis of obese individuals depending on BMI rather than BF\%. For diagnosis of blood glucose disturbance, it is important clinically to assess BF\% and not depending on BMI particularly in those with $\mathrm{BMI}<25 \mathrm{Kg} / \mathrm{m}^{2}$ and their age over 40 years.

\section{References}

1. James WP (2008) The epidemiology of obesity: the size of the problem. J Intern Med 263: 336-352.

2. World Health Organization (1998) Obesity: prevention and managing the global epidemic, Report of a WHO Consultation on Obesity. WHO Technical Report Series No 894.

3. Haslam DW, James WP (2005) Obesity. Lancet 366: 1197-1209.

4. Rodríguez A, Catalán V, Gómez-Ambrosi J, Frühbeck G (2007) Visceral and subcutaneous adiposity: are both potential therapeutic targets for tackling the metabolic syndrome? Curr Pharm Des 13: 2169-2175.

5. Janiszewski PM, Janssen I, Ross R (2007) Does waist circumference predict diabetes and cardiovascular disease beyond commonly evaluated cardiometabolic risk factors? Diabetes Care 30: 3105-3109.

6. Segal KR, Dunaif A, Gutin B, Albu J, Nyman A, et al. (1987) Body composition, not body weight, is related to cardiovascular disease risk factors and sex hormone levels in men. J Clin Invest 80: 1050-1055.

7. Dervaux N, Wubuli M, Megnien JL, Chironi G, Simon A (2008) Comparative associations of adiposity measures with cardiometabolic risk burden in asymptomatic subjects. Atherosclerosis 201: 413-417.

8. Lahmann PH, Lissner L, Gullberg B, Berglund G (2002) A prospective study of adiposity and all-cause mortality: the Malmö Diet and Cancer Study. Obes Res 10: 361-369.

9. Romero-Corral A, Somers VK, Sierra-Johnson J, Korenfeld Y, Boarin S, et al. (2010) Normal weight obesity: a risk factor for cardiometabolic dysregulation and cardiovascular mortality. Eur Heart J 31: 737-746.

10. Heitmann BL, Erikson H, Ellsinger BM, Mikkelsen KL, Larsson B (2000) Mortality associated with body fat, fat-free mass and body mass index among 60-year-old swedish men-a 22-year follow-up. The study of men born in 1913. Int J Obes Relat Metab Disord 24: 33-37. 
Citation: Mohammed SJ (2017) Association between Percentage of Body Fat in Normal Body Mass Index Subjects and Type 2 Diabetes Mellitus in Iraqi Population: Case Control Study. J Diabetes Metab 8: 770. doi:10.4172/2155-6156.1000770

Page 3 of 3

11. Gomez-Ambrosi J, Salvador J, Rotellar F, Silva C, Catalán V, et al. (2006) Increased serum amyloid A concentrations in morbid obesity decrease after gastric bypass. Obes Surg 16: 262-269.

12. Gomez-Ambrosi J, Catalan V, Ramirez B, Rodríguez A, Colina I, et al. (2007) Plasma osteopontin levels and expression in adipose tissue are increased in obesity. J Clin Endocrinol Metab 92: 3719-3727.

13. Prentice AM, Jebb SA (2001) Beyond body mass index. Obes Rev 2: 141-147.

14. Bosy-Westphal A, Geisler C, Onur S, Korth O, Selberg O, et al. (2006) Value of body fat mass vs anthropometric obesity indices in the assessment of metabolic risk factors. Int J Obes (Lond) 30: 475-483.

15. Shen W, Punyanitya M, Chen J, Gallagher D, Albu J, et al. (2006) Waist circumference correlates with metabolic syndrome indicators better than percentage fat. Obesity (Silver Spring) 14: 727-736.

16. Romero-Corral A, Somers VK, Sierra-Johnson J, Korenfeld Y, Boarin S, et al. (2010) Normal weight obesity: a risk factor for cardiometabolic dysregulation and cardiovascular mortality. Eur Heart J 31: 737-746.

17. ADA (2004) Screening for type 2 diabetes. Diabetes Care 27: S11-S14.

18. Ealovega MW, Tabaei BP, Brandle M, Burke R, Herman WH (2004) Opportunistic screening for diabetes in routine clinical practice. Diabetes Care 27: 9-12.

19. Wildman RP, Muntner P, Reynolds K, McGinn AP, Rajpathak S, et al (2008) The obese without cardiometabolic risk factor clustering and the normal weight with cardiometabolic risk factor clustering: prevalence and correlates of 2 phenotypes among the US population (NHANES 1999-2004). Arch Intern Med 168: 1617-1624.

20. Wang Y, Rimm EB, Stampfer MJ, Willett WC, Hu FB (2005) Comparison of abdominal adiposity and overall obesity in predicting risk of type 2 diabetes among men. Am J Clin Nutr 81: 555-563.

21. MacKay MF, Haffner SM, Wagenknecht LE, D’Agostino RB Jr, Hanley AJ (2009) Prediction of type 2 diabetes using alternate anthropometric measures in a multi-ethnic cohort: the insulin resistance atherosclerosis study. Diabetes Care 32: 956-958.

22. Biggs ML, Mukamal KJ, Luchsinger JA, Ix JH, Carnethon MR, et al. (2010) Association between adiposity in midlife and older age and risk of diabetes in older adults. JAMA 303: 2504-2512.

23. Pou KM, Massaro JM, Hoffmann U, Vasan RS, Maurovich-Horvat P, et al. (2007) Visceral and subcutaneous adipose tissue volumes are crosssectionally related to markers of inflammation and oxidative stress: the Framingham Heart Study. Circulation 116: 1234-1241.

24. Ferrante AW Jr (2007) Obesity-induced inflammation: a metabolic dialogue in the language of inflammation. J Intern Med 262: 408-414.

25. Sierra-Johnson J, Johnson BD, Bailey KR, Turner ST (2004) Relationships between insulin sensitivity and measures of body fat in asymptomatic men and women. Obes Res 12: 2070-2077. 